\title{
Numerical Simulation and Thermophysical Feature Analysis of Fire Propagation Law in Large Urban Rail Transit Buildings
}

\author{
Xiangling Duanmu ${ }^{1,2^{*}}$, Zina Zhan ${ }^{1,2}$, Yunlong Song ${ }^{1,2}$ \\ ${ }^{1}$ China Academy of Building Research, Beijing 100013, China \\ ${ }^{2}$ Fire Safety Science \& Technology Co., Ltd., Beijing 100013, China
}

Corresponding Author Email: duanmuxiangling@163.com

https://doi.org/10.18280/ijht.390635

Received: 28 August 2021

Accepted: 2 November 2021

\section{Keywords:}

urban rail transit (URT), fire propagation

law, thermophysical features

\begin{abstract}
As the development of urban rail transit (URT) picks up speed, more and more attention has been paid to the safety hazards that threaten URT operations. In URT buildings with different fire resistance ratings, the combustion performance and fire resistance limit of their components must meet relevant national standards. It is of certain practical significance to explore the fire propagation law in large modern URT buildings. Considering the peculiarity of URT building fire, this paper carries out numerical simulation and thermophysical feature analysis of fire propagation law. Firstly, the fire propagation features in underground station and section (USS) of URT system were described, and the corresponding control equations were established for mass, momentum, and energy. Then, the factors affecting the attenuation coefficient, including heat exchange coefficient, convection coefficient, and radiation coefficient, were analyzed, and a prediction model was established for temperature attenuation. Experiments were carried out to verify the scientific nature of our numerical simulation of fire propagation law in URT buildings, and obtain the thermophysical properties of fire propagation in URT buildings.
\end{abstract}

\section{INTRODUCTION}

Urbanization is picking up speed year by year. The urban rail transit (URT) has become an integral part of modern urban transport system, thanks to its fast speed, large volume, low pollution, and high punctuality [1-6]. As the passenger traffic of the URT grows annually, the safety of the URT system has attracted more and more attention. Fire is the leading hidden hazard that threatens the operational safety of the URT [7-12]. The complex buildings in the URT system, ranging from station, section, vehicle base, to control center, belong to varied fire resistance ratings. Their components must meet relevant national standards [13-19]. To safeguard people's lives and properties, it is important to study the fire propagation law in large modern URT buildings.

Fire protection facilities are critical to the fire safety of public facilities. With the extension of service time of metros in major cities, severe fire safety problems have emerged in a growing number of URTs. Through field surveys and information query, Yang et al. [20] surveyed the current state of URT fire protection facilities, and summarized the common problems, namely, equipment aging, improper design, equipment maloperation, and mismatch between design, construction, and operation. Several improvement measures were proposed to overcome these problems. To make up for the high vulnerability of the URT to fire, Wang et al. [21] improved the theory of URT vulnerability evaluation, introduced the basic knowledge of URT vulnerability and its influencing factors, and put forward a new method to verify the effectiveness of URT vulnerability control measures.

The URT improves urban spatial structure, and solves urban traffic congestion. The safety issue of the URT system cannot be ignored. Fire poses a major threat to the safety of the URT. Targeting the underground stations and sections from Wenjiao Road to Maqing Road on Line 2, Xiamen Metro, Zhang et al. [22] used Fire Dynamics Simulator (FDS) to simulate the mechanical exhaust of vertical shafts in main underground stations and sections at different wind speeds, and deeply analyzed the smoke and temperature distributions when a fire breaks out at these underground stations and sections. Considering the flow field structure of fire platform in different scenes, as well as the temperature and speed distributions at specific locations, Zhong et al. [23] adopted three methods to reduce the influence of piston on the smoke layer. The results show that the piston wind would induce a large vortex and a huge horizontal inertia. To limit the dangerous smoke of fire floors, Zhong et al. [23] recommended increasing the boosted volume flow of the hall, and reducing the smoke screen height around the stairs.

Building fires have been mainly studied through experiments or computer simulations. Some scholars discussed the influence of burning zone location over fire propagation in large buildings, and some examined the fire growth through fluid dynamics numerical simulation. Nevertheless, very few researchers have studied the fire prevention and thermophysical features of fire propagation in URT buildings. Considering the peculiarity of URT building fire, this paper carries out numerical simulation and thermophysical feature analysis of fire propagation law. Section 2 describes the fire propagation features in underground station and section (USS) of URT system, and constructs the corresponding control equations for mass, 
momentum, and energy. Section 3 analyzes the factors affecting the attenuation coefficient, including heat exchange coefficient, convection coefficient, and radiation coefficient, and builds up a prediction model for temperature attenuation. Finally, experiments were carried out to verify the scientific nature of our numerical simulation of fire propagation law in URT buildings, and obtain the thermophysical properties of fire propagation in URT buildings.

\section{BASIC CONTROL EQUATIONS}

In the URT system, the following buildings belong to level 1 of fire resistance rating: underground station and its entry and exit channels, airways, underground section, service channels, sectional air shafts and airways, control center, main substation, flammable warehouse, paint warehouse, and other buildings in the vehicle base. The following buildings belong to level 1 of fire resistance rating: surface station and surface section, the surface hall of the entrances and exits of underground station, ventilation pavilions, and other surface buildings; utility warehouse, maintenance warehouse, integrated maintenance building (of the comprehensive maintenance center), central material warehouse, shunting warehouse, mixed traction and step-down substation, car washer warehouse, engineering vehicle warehouse, integrated office building, and other auxiliary buildings.

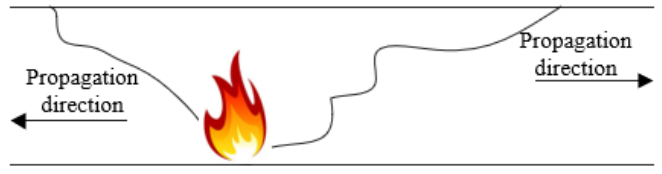

(1)

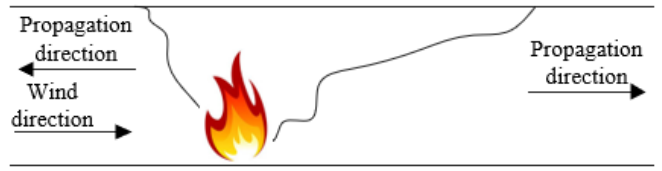

(2)

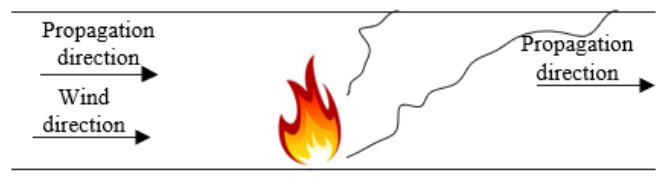

(3)

Figure 1. Fire propagation in USS of the URT

Figure 1 illustrates the fire propagation in USS of the URT. It can be inferred that adding a horizontal wind to URT USS can suppress the hot flue gas flow to a certain extent. According to the Richardson's law, this paper firstly describes the fire propagation in USS of the URT, and establishes the control equations of mass, momentum, and energy. Through full consideration of the cross-sectional size, convection, and radiation of the USS, the authors further constructed the horizontal attenuation law model for fire temperature along the underground section.

Let $\dot{n}$ be the mass flow rate of the hot flue gas flow in the USS; $g$ be the thickness of the hot flue gas flow; $Y$ be the thickness of the interface between the hot flue gas flow and the underlying air; $\Phi_{x}$ be the ambient temperature; $\phi_{x}$ be the density of the ambient air; $d_{o}$ be the specific heat at constant pressure; $v_{f}$ be the horizontal entrainment coefficient; $\hat{u}$ be the heat exchange power between USS hot flue gas flow, and the walls and the environment; $h$ be the duration of fire.

The thermophysical variation of the hot flue gas flow of USS fire is considered in the direction a. Since the hot flue gas flow is an incompressible fluid, the specific heat $d_{w}$ of the flow equals $d_{o}$. Concerning the convection between the hot flue gas flow of USS fire, and the walls and the environment, the basic control equation of USS fire propagation can be established for each control parameter:

$$
\begin{aligned}
& \frac{d}{d h}\left(\varphi_{i, j} d a d c\right)= \\
& \dot{n}_{i-1, j \rightarrow i, j}-\dot{n}_{i, j \rightarrow i+1, j}+\dot{n}_{i, j-1 \rightarrow i, j}-\dot{n}_{i, j \rightarrow i, j+1}
\end{aligned}
$$

For the basic control equation, the upper boundary of the hot flue gas layer satisfies

$$
\dot{n}_{i, j \rightarrow i, j+1}=0
$$

Let $\dot{n}_{v}$ be the underlying cold air under the horizontal entrainment by the hot flue gas flow. Then, the lower boundary of the hot flue gas layer satisfies:

$$
\dot{n}_{i, j-1 \rightarrow i, j}=\dot{n}_{v}
$$

The energy equation of USS fire propagation can be established as:

$$
\begin{aligned}
& \frac{d}{d h}\left(d_{o} \varphi_{i, j} \operatorname{dadc} \Phi_{i, j}\right)= \\
& d_{o}\left(\begin{array}{l}
\dot{n}_{i-1, j \rightarrow i, j} \Phi_{i-1, j}-\dot{n}_{i, j \rightarrow i+1, j} \Phi_{i, j} \\
+\dot{n}_{i, j-1 \rightarrow i, j} \Phi_{i, j-1}-\dot{n}_{i, j \rightarrow i, j+1} \Phi_{i, j}
\end{array}\right) \\
& -\dot{u}_{d, i, j}-\dot{u}_{s, i, j}=d_{o} \frac{d(\dot{n} \Phi)}{d a}+ \\
& d_{o} \frac{d(\dot{n} \Phi)}{d c} d c-\dot{u}_{d, i, j}-\dot{u}_{s, i, j}
\end{aligned}
$$

For the energy function, the upper boundary of the hot flue gas layer satisfies:

$$
\dot{n}_{i, j \rightarrow i, j+1}=0
$$

Let $\dot{n}_{v} \Phi_{x}$ be the underlying cold air under the horizontal entrainment by the hot flue gas flow. Then, the lower boundary of the hot flue gas layer satisfies:

$$
\dot{n}_{i, j-1 \rightarrow i, j} \Phi_{i, j-1}=\dot{n}_{v} \Phi_{x}
$$

During the fire propagation, the hot flue gas flow continues to entrain the underlying cold air. Hence, the mass flow rate and thickness of the hot flue gas flow keep growing [24]. The enthalpy of the hot flue gas flow depends on the enthalpy of the entrained cold air, the convective heat loss, and radiative heat loss. For the entrainment process:

$$
\dot{n}_{v}=\varphi_{x} v_{f} Y
$$

The two-dimensional (2D) basic control equation can be 
simplified as one-dimensional (1D) basic control equation for the mass and energy of the hot flue gas flow:

$$
\frac{d \dot{n}}{d a}=\varphi_{x} v_{f} Y
$$

The energy equation can be given by:

$$
\frac{d}{d a}\left(d_{o} \dot{n} \Phi\right)=d_{o} v_{f} Y \varphi_{x} \Phi_{x}+\dot{u}
$$

Let $\beta$ be heat exchange coefficient; $\Phi_{v}$ be the USS wall temperature; $P$ be the length of the perimeter of the crosssectional area of hot flue gas flow in contact with USS walls. Then, the heat exchange power between USS walls, soil environment, and hot flue gas flow can be calculated by:

$$
\dot{u}=\beta P\left(\Phi_{v}-\Phi\right)=\beta P\left(\Phi_{x}-\Phi\right)
$$

Through the above analysis, the basic equation can be further simplified as a continuous equation:

$$
\frac{d \dot{n}}{d a}=\varphi_{x} v_{f} Y
$$

The corresponding energy equation can be expressed as:

$$
\frac{d}{d a}\left(d_{o} \dot{n} \Phi\right)=d_{o} v_{f} Y \varphi_{x} \Phi_{x}+\beta P\left(\Phi_{x}-\Phi\right)
$$

The left side of Eq. (12) can be expanded as:

$$
\begin{aligned}
& d_{o} \frac{d \dot{n}}{d a} \Phi+d_{o} \dot{n} \frac{d \Phi}{d a}= \\
& d_{o} \varphi_{x} v_{f} Y \Phi_{x}+\beta P\left(\Phi_{x}-\Phi\right)
\end{aligned}
$$

Combining formulas (11) and (13):

$$
\begin{gathered}
d_{x} \varphi_{x} v_{f} Y \Phi+d_{o} \dot{n} \frac{d \Phi}{d a}= \\
d_{o} \varphi_{x} v_{f} Y \Phi_{x}+\beta P\left(\Phi_{x}-\Phi\right) \\
\Rightarrow d_{o} \dot{n} \frac{d \Phi}{d a}=d_{o} \varphi_{x} v_{f} Y\left(\Phi_{x}-\Phi\right)+\beta P\left(\Phi_{x}-\Phi\right) \\
\Rightarrow d_{o} \dot{n} \frac{d \Phi}{d a}=\left(d_{o} \varphi_{x} v_{f} Y+\beta P\right)\left(\Phi_{x}-\Phi\right)
\end{gathered}
$$

Solving formula (11) and substituting boundary conditions $a=0$ and $\dot{n}=\dot{n}_{0}$ :

$$
\dot{n}=\dot{n}_{0}+\varphi_{x} v_{f} Y a
$$

Combining formulas (16) and (17):

$$
\frac{d \Phi}{\left(\Phi_{x}-\Phi\right)}=\frac{\beta P+d_{o} \varphi_{x} v_{f} Y}{d_{o}\left(\dot{n}_{0}+\varphi_{x} v_{f} Y a\right)} d a
$$

Taking the integral on both sides of Eq. (18) in the interval of $0 \rightarrow a$, and substituting the boundary conditions:

$$
\left\{\begin{array}{l}
\frac{d \Phi}{\Phi_{x}-\Phi}=\frac{\beta P+d_{o} \varphi_{x} v_{f} Y}{d_{o}\left(\dot{n}_{0}+\varphi_{x} v_{f} Y a\right)} d a \\
a=a_{0}, \Phi=\Phi_{0}
\end{array}\right.
$$

During the fire propagation, as the hot flow gas flow continuously entrains underlying cold air, the parameters $\mathrm{P}$ and $\mathrm{Y}$ will change with the growing distance of fire propagation. Let $g_{0}$ be the initial boundary value of the hot flue gas flow; q be the horizontal propagation speed of the hot flue gas flow. Then, the following can be derived from formula (11):

$$
\frac{d \dot{n}}{d g}=\varphi q Y
$$

Taking the integral of the above formula:

$$
g=g_{0}+\frac{v_{f}}{q} a
$$

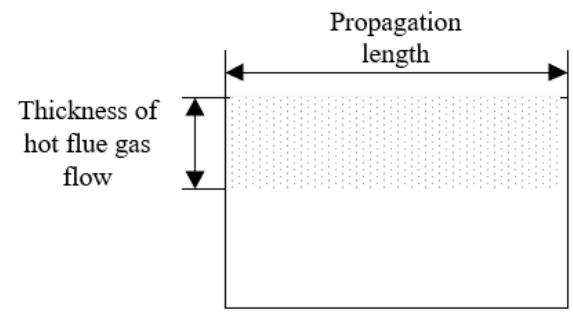

(1)

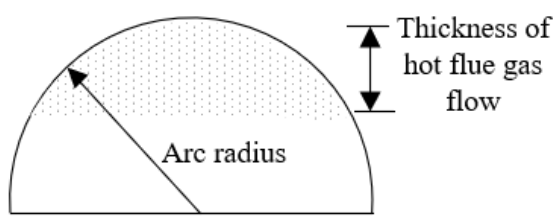

(2)

Figure 2. Two types of USS tops

Figure 2 illustrates the two kinds of USS tops. Parameters $\mathrm{P}$ and Y vary with the top types. Let $\Psi$ be a constant, If the USS has a rectangular top, there is:

$$
\begin{gathered}
P=Y+2\left(g_{0}+\frac{v_{f}}{q} a\right) \\
Y=\Psi
\end{gathered}
$$

Let $\mathrm{S}$ be the arc radius. If the USS has an arc top, there is:

$$
\begin{gathered}
P=2 S \cdot \arccos \left(\frac{S-g}{S}\right) \\
Y=2 \sqrt{g(2 S-g)}
\end{gathered}
$$

For arc-top USS, combining formulas (22), (23) and (19): 


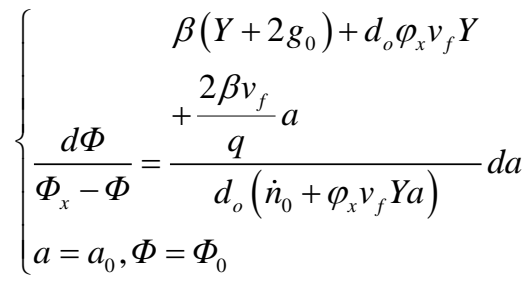

Taking the integral of the above formula:

$$
\begin{aligned}
& \frac{\Delta \Phi}{\Delta \Phi_{0}}= \\
& \left.\left[1+\frac{d_{o} \varphi_{x} v_{f} Y}{d_{o} \dot{n}_{0}}\left(a-a_{0}\right)\right]\right]^{\frac{\left(\beta \gamma+2 \beta g_{0}+d_{o} \varphi_{x} v_{f} Y\right) d_{o} \varphi_{x} v_{f} Y-2 d_{o} \dot{n}_{0} \beta v_{f} / q}{\left(d_{o} \varphi_{x} v_{f} Y\right)^{2}}} \\
& \cdot e^{\frac{2 \beta v_{f}}{q d_{o} \varphi_{x} v_{f} Y}\left(a-a_{0}\right)}
\end{aligned}
$$

The horizontal entrainment coefficient $v_{f}$ can be calculated by:

$$
v_{f}=\gamma q
$$

The $\gamma$ value can be empirically taken as 0.00014 . Ignoring the horizontal entrainment volume:

$$
\frac{d_{o} \varphi_{x} v_{f} Y}{d_{o} \dot{n}_{0}} \rightarrow 0
$$

Combining formulas (27) and (29) and solving the limit:

$$
\frac{\Delta \Phi}{\Delta \Phi_{0}}=e^{-L\left(a-a_{0}\right)}
$$

where,

$$
L=\frac{\beta P}{d_{o} \dot{n}}
$$

\section{ANALYSIS OF ATTENUATION MECHANISM}

\subsection{Influencing factors of attenuation coefficient}

The temperature of the hot flue gas in the USS extends along the section, exhibiting an exponential attenuation trend. The attenuation coefficient is directly related to the convection coefficient between hot flue gas flow, and USS wall and soil environment, the shape and size of USS cross-section, and the mass flow rate of hot flue gas flow in the fire. Among them, the convection between hot flue gas flow, and USS wall and soil environment mainly covers two parts: convective heat loss, and radiative heat loss. The heat exchange coefficients of two cases, namely, the hot flue gas flow reaches the ground (case 1) and the hot flue gas flow does not reach the ground (case 2), can be expressed as:

$$
\beta=\left\{\begin{array}{l}
f_{d}+f_{s}, \text { Case } 1 \\
f_{d}+f_{s} \frac{P+Y}{P}, \text { Case } 2
\end{array}\right.
$$

Concerning the influencing factors of attenuation coefficient, the empirical relationship coefficient is denoted as $L^{\prime}$. The convection coefficient between hot flue gas flow, and USS wall and soil environment can be calculated by:

$$
g_{d}=2 L^{\prime} \sqrt{q}
$$

Let $\sigma$ be the radiation rate; $\varepsilon$ be the Boltzmann constant; $\Phi_{r}$ be the temperature of hot flue gas flow. Then, the radiation coefficient can be calculated by:

$$
g_{s}=\sigma \varepsilon\left(\Phi_{r}+\Phi_{v}\right)\left(\Phi_{r}^{2}+\Phi_{v}^{2}\right)
$$

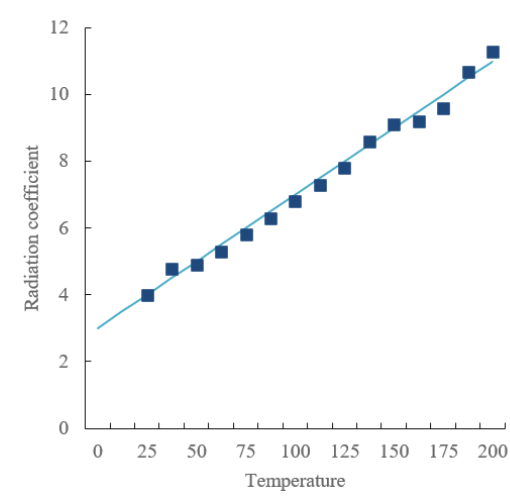

Figure 3. Radiation coefficient curve at different temperatures

Figure 3 shows the radiation coefficient curve at different temperatures. According to the figure and the above analysis, the radiation coefficient of the hot flue gas flow of USS fire is associated with the temperature at the location of the flue gas flow. The higher the latter temperature, the larger the radiation coefficient.

\subsection{Temperature attenuation prediction model}

The empirical relationship constant $L^{\prime}$ is set to 8. Then, the total heat transfer coefficient of the hot flue gas flow of USS fire can be calculated by:

$$
\beta=\left\{\begin{array}{l}
16 \sqrt{q}+g_{s}, \text { Case } 1 \\
16 \sqrt{q}+g_{s} \frac{P+Y}{P}, \text { Case } 2
\end{array}\right.
$$

Let $\mathrm{R}$ be the cross-sectional size of the hot flue gas flow. Then, the mass flow rate of the hot flue gas flow of USS fire can be estimated by:

$$
\dot{n}=\varphi q R
$$

Substituting the above relationship formula, the attenuation coefficient of the temperature distribution of the hot flue gas in the USS can be calculated by:

$$
\mu=\left\{\begin{array}{l}
\frac{0.001 \cdot\left(16 \sqrt{q} P+g_{s}\right)(P+Y)}{d_{o} \varphi q R}, \text { Case } 1 \\
\frac{0.001 \cdot\left[16 \sqrt{q} P+g_{s}(P+Y)\right]}{d_{o} \varphi q R}, \text { Case } 2
\end{array}\right.
$$


As mentioned before, parameters $\mathrm{P}$ and $\mathrm{Y}$ vary with the types of USS top. If the USS has a rectangular top, the attenuation coefficient can be calculated by:

$$
\mu=\left\{\begin{array}{l}
0.001 \cdot\left[\begin{array}{l}
16 \sqrt{q}(V+2 g) \\
+2 g_{s}(V+g)
\end{array}\right] \\
\frac{d_{o} \varphi q V g}{0.001 \cdot 2\left(16 \sqrt{q}+g_{s}\right)(V+G)} \\
\frac{d_{o} \varphi q V G}{g}, g=G
\end{array}\right.
$$

If the USS has an arc top, the attenuation coefficient can be calculated by:

$$
\mu=\left\{\begin{array}{l}
0.035 \sqrt{q} S \arccos \frac{S-g}{S} \\
+0.002 g_{s}\left[\begin{array}{l}
\left.S \arccos \frac{S-g}{S}\right] \\
+\sqrt{g(2 S-g)}]
\end{array}\right] \\
d_{o} \varphi q\left[\begin{array}{l}
\left.S^{2} \arccos \frac{S-g}{S}\right] \\
-(S-g) \sqrt{g(2 S-g)}]
\end{array}\right] G \\
\frac{0.035 \sqrt{q} S \pi+0.002 g_{s} S(\pi+2)}{d_{o} \varphi q S^{2} \pi}, g=G
\end{array}\right.
$$

Since $d_{o}$ and $\sigma$ are approximately constant, how the temperature of the hot flue gas flow of the USS fire attenuates in the propagation length can be predicted based on the known top size of the USS, the propagation speed of the hot flue gas flow, the thickness of the hot flue gas flow, and the mean radiation coefficient of the hot flue gas flow in the propagation length.

\section{EXPERIMENTS AND RESULTS ANALYSIS}

The experimental USS is located in an underground building of an URT system, which is under construction. The building framework has been completed. There is a $116 \mathrm{~m}$-long, 80 -wide passage in the west of basement 1 of the building. The support beams of the arc top are basically completed. During the experiment, an exhaust port was arranged at the north end and south end of the USS, respectively. Each exhaust port was connected to two exhaust fans. The temperature, smoke front location, flue gas layer height, and fire source power were measured by a large space distributed temperature measurement and acquisition module.

According to the initial development speed, an USS fire can be divided into four types: ultrafast, fast, medium, and slow. Figure 4 shows how heat release rate changes with the fire duration, under different fire sources. Because USS fires mostly hit flammable objects, they usually belong to the ultrafast type. As shown in Figure 4, it only took 184 s to reach the maximum heat release power, when the fire source power was $10 \mathrm{MW}$. Figure 5 displays the temperature variation of the hot flue gas flow in the horizontal direction at different exhaust speeds. It can be observed that the maximum temperature of the hot flue gas flow slightly increased, with the extension of fire duration. When the propagation speed reached $2.25 \mathrm{~m} / \mathrm{s}$, the hot flue gas near the fire point was not completely blown downstream, resulting in a peak of measured temperature. When the propagation speed was lower than or higher than $2.25 \mathrm{~m} / \mathrm{s}$, the measured temperature was relatively low, because the flue gas flows back or moves to the downstream in large quantities.

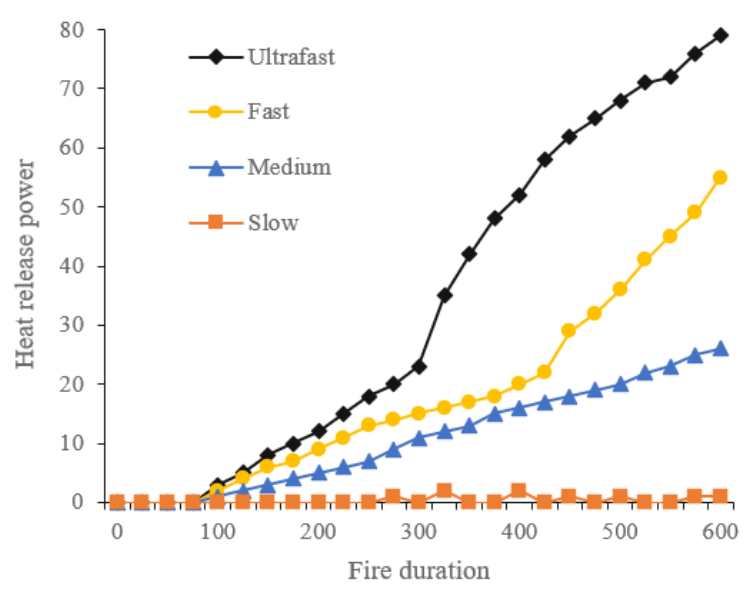

Figure 4. Heat release rate vs. fire duration

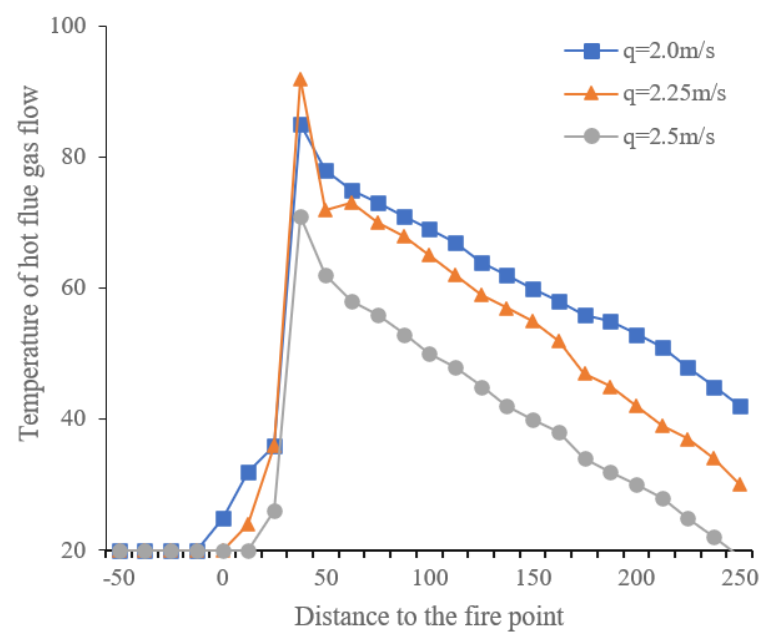

Figure 5. Temperature variation of the hot flue gas flow in the horizontal direction at different exhaust speeds

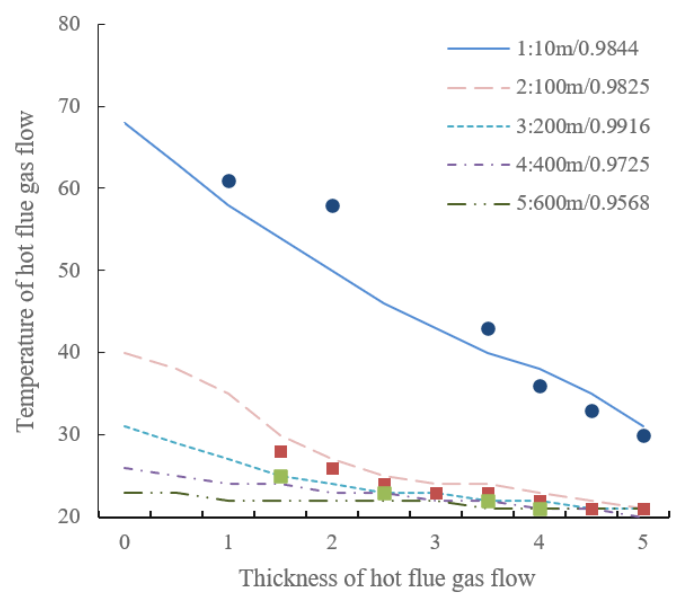

Figure 6. Vertical temperature distribution of the hot flue gas flow 
Table 1. Predicted and fitted values of the attenuation coefficient of the temperature of the hot flue gas flow in the horizontal direction

\begin{tabular}{ccccccccc}
\hline & Test number & 1 & 2 & 4 & 5 & 6 & 7 & 8 \\
\hline & $\boldsymbol{q}$ & 3.2 & 2.5 & 1.5 & 2.5 & 1.4 & 2.6 & 2.2 \\
$\boldsymbol{P}$ & 20.7 & 16.8 & 15 & 18.4 & 14.6 & 14.8 & 15.7 \\
& $\boldsymbol{Y}$ & 14.8 & 12.6 & 11.2 & 12.4 & 12.6 & 11.4 & 11.7 \\
& $\boldsymbol{g}_{\boldsymbol{d}}$ & 31.2 & 28.1 & 23 & 31.5 & 25 & 27.9 & 25.2 \\
& $\boldsymbol{g}_{\boldsymbol{s}}$ & 4.2 & 4.5 & 4.2 & 4.6 & 4.1 & 4.8 & 4.4 \\
& $\boldsymbol{R}$ & 65.2 & 42.7 & 41.5 & 56.8 & 32.8 & 37 & 35.9 \\
& Predicted value & 0.0158 & 0.0142 & 0.0258 & 0.0144 & 0.0174 & 0.0315 & 0.0295 \\
$\boldsymbol{\mu}$ & Fitted value & 0.0143 & 0.0375 & 0.0247 & 0.0315 & 0.0415 & 0.03326 & 0.0352 \\
& Fitting correlation & 0.9877 & 0.9596 & 0.9958 & 0.9958 & 0.9647 & 0.9485 & 0.9752 \\
\hline
\end{tabular}

Figure 6 presents the vertical temperature distribution of the hot flue gas flow: The temperature of the hot flue gas flow decreased with the growing distance from the top. Overall, the temperature of the hot flue gas flow is clearly linearly distributed in the vertical direction. This paper linearly fits the collected temperature data. The correlation coefficient was always greater than 0.9 , indicating a good fitting effect.

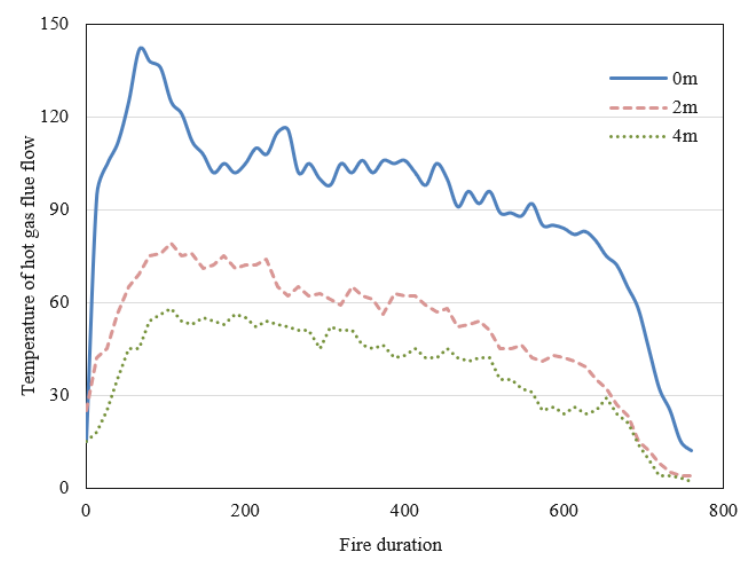

Figure 7. Result of first test on the USS

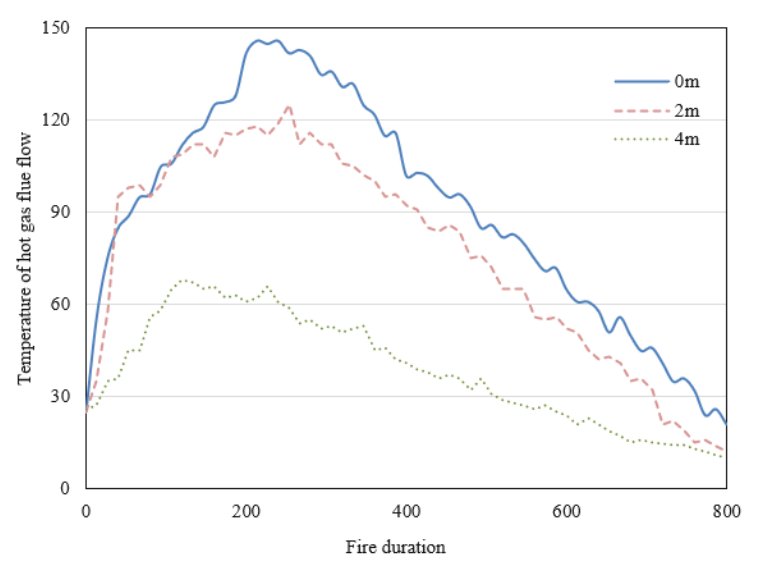

Figure 8. Result of second test on the USS

Two USS experiments were carried out under basically the same conditions: the ambient wind speeds were both small (as show in Figures 7 and 8). Therefore, during the initial phase of the fire, the temperature of the hot flue gas flow near the top was basically the same within $6 \mathrm{~m}$ on both sides of the fire point. When the distance to the fire point was greater than $6 \mathrm{~m}$, the upstream temperature of the hot flue gas flow was $10^{\circ} \mathrm{C}$ higher than the downstream temperature.
The cross-sectional size $\mathrm{R}$, as well as $\mathrm{P}$ and $\mathrm{Y}$ of the hot flue gas flow can be derived from the mean thickness of the hot flue gas flow, and the cross-sectional size of the USS. These parameters, along with the actual propagation speed $\mathrm{q}$ of the hot flue gas flow, convection coefficient $g_{d}$, and radiation coefficient $g_{s}$, were imported to the proposed numerical simulation model to compute the attenuation coefficient $\mu$ of the temperature of the hot flue gas flow in the horizontal direction in multiple tests. Table 1 sums up the predicted and fitted values. It can be learned that, when the hot flue gas flow was thick, the cross-sectional size, mass, and flow rate of the gas flow were all relatively large, resulting in a large thermal capacity of the gas flow. As a result, the attenuation coefficient of the temperature of the hot flue gas flow was small in the horizontal direction. This is in line with our expectation before the experiments.

\section{CONCLUSIONS}

Focusing on the special fire in URT buildings, this paper numerically simulates the fire propagation law, and explores the thermophysical features of the fire. After studying the propagation features of URT USS fire, the authors established the corresponding control equations were established for mass, momentum, and energy. Next, a thorough analysis was carried out on the factors affecting the attenuation coefficient, including heat exchange coefficient, convection coefficient, and radiation coefficient. Finally, a model was constructed to predict temperature attenuation. During the experiments, the variation of heat release rate with fire duration was plotted, and used to derive the moment that the fire source power reaches the maximum heat release power. In addition, the horizontal temperature variation of the hot flue gas flow was analyzed at different exhaust speeds, the variation of heat release rate with fire duration was examined under different fire sources, and the vertical temperature distribution was obtained for the hot flue gas flow. In the end, eight tests were completed to measure the horizontal attenuation coefficient of the temperature of the hot flue gas flow. The experimental results agree with our expectation, and demonstrate the scientific nature of the proposed numerical simulation strategy for the propagation law of URT building fire.

\section{ACKNOWLEDGMENT}

This paper is funded by CABR Scientific Research Fund (Grant No.: 20190111330730002). 


\section{REFERENCES}

[1] Huang, C., Huang, Y. (2021). Urban rail transit signal and control based on internet of things. Journal of High Speed Networks, 27(3): 237-250. https://doi.org/10.3233/JHS-210664

[2] Deng, L.B., Duan, K.Y., Wang, Q., Shi, F.S. (2021). Energy-efficient optimization method for urban rail transit timetable. Systems Engineering - Theory \& Practice, 41(6): 1486-1495. https://doi.org/10.12011/SETP2019-1526

[3] Gu, J., Yang, X., Zheng, T.Q. (2018). Influence factors analysis of rail potential in urban rail transit. Microelectronics Reliability, 88-90: 1300-1304. https://doi.org/10.1016/j.microrel.2018.07.039

[4] Zhao, X., Hou, Z., Chen, J., Zhang, Y., Sun, J. (2018). Urban rail transit scheduling under time-varying passenger demand. Journal of Advanced Transportation, 2018. Article ID 7285148 https://doi.org/10.1155/2018/7285148

[5] Wang, Z.Q., Zhang, M., Xu, R.H. (2007). Emergency treatment assistant decision system of urban rail transit. In International Conference on Transportation Engineering, pp. 3707-3713. https://doi.org/10.1061/40932(246)608

[6] Xu, J., Jia, L. M., Qin, Y., Wang, Y.H., Wang, Z. (2007). Study on integrated monitor and control system for urban rail transit. Journal of the China Railway Society, 29(3): 107-112.

[7] Wang, K., Cai, W., Zhang, Y., Hao, H., Wang, Z. (2021). Numerical simulation of fire smoke control methods in subway stations and collaborative control system for emergency rescue. Process Safety and Environmental Protection, 147: 146-161. https://doi.org/10.1016/j.psep.2020.09.033

[8] Li, Y., Rong, W. (2021). Analysis of subway fire accident based on Bayesian network. In Journal of Physics: Conference Series, 1910(1): 012039. https://doi.org/10.1088/1742-6596/1910/1/012039

[9] Lei, W., Li, A., Tai, C. (2017). The effect of different fire source locations on the environment of a subway station. Procedia Engineering, 205: 3721-3726. https://doi.org/10.1016/j.proeng.2017.10.305

[10] Peng, M., Cheng, X., Cong, W., Yuen, R. (2021). Experimental investigation on temperature profiles at ceiling and door of subway carriage fire. Fire Technology, 57(1): 439-459. https://doi.org/10.1007/s10694-020-01010-Z

[11] Wang, Z., Zhu, L., Guo, X., Pan, X., Zhou, B., Yang, J., Feng, L. (2019). Reduced-scale experimental and numerical study of fire in a hybrid ventilation system in a large underground subway depot with superstructures under fire scenario. Tunnelling and Underground Space Technology, 88: 98-112. https://doi.org/10.1016/j.tust.2019.02.006

[12] Guo, X., Pan, X., Wang, Z., Yang, J., Hua, M., Jiang, J. (2018). Numerical simulation of fire smoke in extra-long river-crossing subway tunnels. Tunnelling and Underground Space Technology, 82: 82-98. https://doi.org/10.1016/j.tust.2018.08.002

[13] Yao, H.W., Meng, D., Zheng, Y.P., Liang, D. (2016).
Analysis on causes of subway fire alarm linkage strategy. In 2016 International Conference on Robots \& Intelligent System (ICRIS), pp. 107-110. https://doi.org/10.1109/ICRIS.2016.22

[14] Yang, X.X., Dong, H.R., Yao, X.M., Sun, X.B. (2016). Pedestrian evacuation at the subway station under fire. Chinese Physics B, 25(4): 048902. https://doi.org/10.1088/1674-1056/25/4/048902

[15] Li, Q., Deng, Y., Liu, C., Zeng, Q., Lu, Y. (2016). Modeling and analysis of subway fire emergency response: An empirical study. Safety Science, 84: 171180. https://doi.org/10.1016/j.ssci.2015.12.003

[16] Meng, N., Wang, Q., Liu, Z., Li, X., Yang, H. (2017). Smoke flow temperature beneath tunnel ceiling for train fire at subway station: Reduced-scale experiments and correlations. Applied Thermal Engineering, 115: 9951003. https://doi.org/10.1016/j.applthermaleng.2017.01.027

[17] Zhao, D., Jiang, J., Zhou, R., Tong, Y., Wu, F., Shi, L. (2016). Numerical study on the optimisation of smoke ventilation mode for interchange subway station fire. International Journal of Ventilation, 15(1): 79-93. https://doi.org/10.1080/14733315.2016.1173294

[18] Ma, J., Miao, Z., Tian, J., Huang, P. (2019). Design of evacuation simulation system for subway station personnel in fire environment based on SPH. In IOP Conference Series: Earth and Environmental Science, 218(1): $012090 . \quad$ https://doi.org/10.1088/1755$1315 / 218 / 1 / 012090$

[19] Zhao, P., Yuan, Z., Yuan, Y., Yu, N., Yu, T. (2019). A study on ceiling temperature distribution and critical exhaust volumetric flow rate in a long-distance subway tunnel fire with a two-point extraction ventilation system. Energies, $12(8)$ : 1411. https://doi.org/10.3390/en12081411

[20] Yang, J.T., Liang, J., He, Q.Z. (2018). Analysis and suggestions on current situation of fire-fighting facilities for urban rail transit. Procedia Engineering, 211: 897-900. https://doi.org/10.1016/j.proeng.2017.12.089

[21] Wang, L., Chen, Y., Zhai, H., Song, S. (2017). Analysis of fire safety risks in urban rail transit. In 2017 4th International Conference on Industrial Economics System and Industrial Security Engineering (IEIS), pp. 16. https://doi.org/10.1109/IEIS.2017.8078599

[22] Zhang, H., Zhang, G., Ran, G.Y., Sun, J.C. (2020). Study on the smoke spread law of a subway tunnel fire under the synergistic action of shaft smoke exhaust and longitudinal ventilation. In IOP Conference Series: Earth and Environmental Science, 544(1): 012005. https://doi.org/10.1088/1755-1315/544/1/012005

[23] Zhong, W., Tu, R., Yang, J.P., Liang, T.S. (2015). A study of the fire smoke propagation in subway station under the effect of piston wind. Journal of Civil Engineering and Management, 21(4): 514-523. https://doi.org/10.3846/13923730.2014.890661

[24] Weng, W., Borggren, J., Li, B., Aldén, M., Li, Z. (2017). A novel multi-jet burner for hot flue gases of wide range of temperatures and compositions for optical diagnostics of solid fuels gasification/combustion. Review of Scientific Instruments, 88(4): 045104. https://doi.org/10.1063/1.4979638 